"Factors affecting the implementation of the taxi Recapitalisation Project: the Department of Transport"

AUTHORS Germinah Evelyn Chiloane-Tsoka

ARTICLE INFO

Germinah Evelyn Chiloane-Tsoka (2016). Factors affecting the implementation of the taxi Recapitalisation Project: the Department of Transport. Problems and Perspectives in Management, 14(4), 25-32. doi:10.21511/ppm.14(4).2016.03

DOI http://dx.doi.org/10.21511/ppm.14(4).2016.03

RELEASED ON Wednesday, 14 December 2016

JOURNAL

"Problems and Perspectives in Management"

FOUNDER

LLC "Consulting Publishing Company "Business Perspectives"

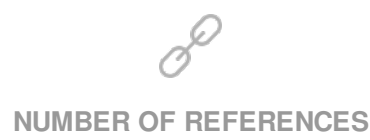

0
NUMBER OF FIGURES

0
NUMBER OF TABLES

0

(C) The author(s) 2022. This publication is an open access article. 


\title{
Factors affecting the implementation of the Taxi Recapitalization Project: the Department of Transport
}

\begin{abstract}
The advent of democracy in 1994 presented the South African government with twin challenges, of significance was institutional transformation while simultaneously introducing new policies in line with the democratic Constitution. In effecting the Constitution, new policies and programs were put in place that would attempt to improve the lives of all citizens. The Taxi Recapitalization Program was amongst challenges facing South African government. The taxi industry plays a crucial role in the economy and contributes $65 \%$ of public commuters taking into consideration that the majority of South Africans are poor and dependent on public transport. Thus, access to public transport is seen as a basic right of all citizens, as enshrined in the Constitution of the Republic of South Africa (108 of 1996, p. 1251). The right of access to public transport has to be complemented with availability, affordability, appropriateness and timelines of a service within a safe and comfortable environment to the satisfaction of those who use public transportation. This paper is based on literature review. Content analysis method was used. The objective of the paper was (i) to investigate factors affecting the implementation of government's TRP by the Department of Transport, (ii) investigate the pillars informing the implementation of the TRP, (iii) establish the role of the South African National Taxi Council (SANTACO) in the implementation of the Taxi Recapitalization Project.
\end{abstract}

Keywords: TRP, SANTACO, SA, DT, taxi associations and policy.

JEL Classification: R41, R42.

\section{Introduction}

As the population grows, it is critical that policy makers should have a plan in place to ensure that transit investment keep pace with growth that increases faster than population growth in order to improve the ability of people to move around cities (RTR, 2014). The Department of Transport in South Africa is confronted with such realities and continues to respond to high road accidents that have continuously left many of the people of South Africa with endless road death mortality. Out of the 36 lives lost daily on our roads, more than 3 are killed in taxi related incidents (Radebe, 2012).

The taxi industry consists of minibuses, dominating $90 \%$ of the market, and metered taxis active in the remaining $10 \%$ of the market. Public transport by taxis accounts for $65 \%$ of the total transport, $20 \%$ by bus and $15 \%$ by rail. The industry consists of approximately 150000 public minibus taxis. The South African taxi industry is estimated to have a turnover of more than R16.5 billion. The minibus taxi industry is comprised of more than 20000 owners and 200000 employees (Fourie, 2015). Taxi recapitalization is the most widely publicized and certainly the most ambitious government intervention in the minibus taxi industry that South African government has initiated since the dawn of democracy (DoT review, 2014). Government seeks to challenge head-on the problem of an ageing fleet within the transportation system. TRP is intended to create opportunities for jobs in the manufacturing and

(C) Germinah Evelyn Chiloane-Tsoka, 2016.

Germinah Evelyn Chiloane-Tsoka, School of Operation and Management sciences, University of South Africa, South Africa. downstream activities, as well as to promote the use of diesel fuel as more cost-effective and efficient fuel and, thus, lower the operating costs, meanwhile, it supports the objective of formalizing the taxi industry through an effective regulatory framework (Mpofu, 2012). In a study conducted by Dlamini-Mokhele (2008, p. 128) on economic impact of TRP regarding the expenditure patterns and poverty levels of taxi operators, the findings of the study suggested that government needs to ensure that it meets its objectives with TRP and that urgent and systematic implementation is required to accelerate TRP. On the contrary, Venter (2009, p. 1) observed that the implementation of the TRP is complex and perceived as not yielding the intended results. Venter (2009) lamented that the journey towards the implementation of the program has not been an easy one and it continues to be challenging. Although there existed different opinions on the implementation of the TRP, a study conducted by Magubane and Manicom (200, p. 9) indicated that there were some perceptions of taxi owners regarding the TRP. In their findings, $77 \%$ of respondents had a positive attitude towards TRP, while $23 \%$ did not support it. Even though the taxi industry showed an understanding of the program in terms of introduction of bigger vehicles and regulated working environment for drivers, it did not include all the intentions of the program. According to Magubane and Manicom (2003, p. 9), the gap was attributed to the lack of knowledge on TRP. The view of Dlamini-Mokhele (2008, p. 128) on the economic impact of TRP on the expenditure patterns would be reasonable to suggest that reservations and concerns about the TRP were raised by most researchers and commentators. The 
above arguments warrant one to conclude that empirical research on TRP is beginning to evolve and there is a need to examine the implementation of the project by the Department of Transport, thereby contributing to the current discourse.

\section{Policy implementation}

Mazmanian and Sabatier (1983, pp. 20-21) define policy implementation as the carrying out of a basic policy decision, usually incorporated in a statute, but which can also take the form of important executive orders or court decisions. The starting point is the authoritative decision. It implies centrally located actors, such as politicians, top-level bureaucrats and others, who are seen as most relevant to producing the desired effects. In their definition, the authors categorize three types of variables affecting the achievement of legal objectives throughout this entire process. These variables can be broadly categorized as:

- tractability of the problem(s) being addressed;

- the ability of the statute to favorably structure the implementation process; and

- the net effect of a variety of political variables on the balance of support for statutory objectives.

O'Toole (2003, p. 266) concurs to the discourse by further defining policy implementation as what develops between the establishment of an apparent intention on the part of government to do something or stop doing something and the ultimate impact of world of actions. More concisely, he notes that policy implementation refers to the connection between the expression of governmental intention and actual result (O'Toole et al., 1995, p. 43).

Nonetheless, Van Meter and Van Horn (1974, pp. 447-448) provide a more specific definition of policy implementation. They define policy implementation as encompassing those actions by public or private individuals (or groups) directed at the achievement of objectives set forth in policy decisions. These authors make a clear distinction between the interrelated concept of implementation, performance and impact and stress. Van Meter and Van Horn observe that impact studies ask "What happened?", whereas implementation studies ask" Why did it happen?" This includes both onetime efforts to transform decisions into operational terms and continuing efforts to achieve the large and small changes mandated by policy. For the purpose of this paper, the definition by Van Meter and Van Horn is chosen, as it asks all the questions required to investigate the factors affecting the implementation of TRP.

As part of policy cycle, policy implementation concerns how governments put policies into effect (Howlett and Ramesh, 2003, p. 13). Elmore (1978, p. 195) identified four main ingredients for effective implementation:
1. clearly specified tasks and objectives that accurately reflect the intent of policy;

2. a management plan that allocates tasks and performance standards to subunits;

3. an objective means of measuring subunit performance; and

4. system of management controls and social sanctions sufficient to hold subordinates accountable for their performance. Failures of implementation are, by definition, lapses of planning, specification and control.

Matland (1995) mentioned in Hill and Hupe (2002, p. 75) argue that successful implementation requires compliance with statutes' directives and goals; achievement of specific success indicators; and improvement in the political climate around a program. In this line, Giacchino and Kakabadse (2003) cited in Paudel (2010, p. 37) note that there are decisions taken to locate political responsibility for initiative; presence of strong project management or team dynamics and level of commitment shown to policy initiatives.

The success of a policy implementation depends critically on two broad factors: local capacity and will. Questions of motivation and commitment (or will) reflect the implementer's assessment of the value of a policy or the appropriateness of a strategy. Motivation or will is influenced by factors largely beyond the reach of policy environmental stability; competing centers of authority, contending priorities or pressures and other aspects of sociopolitical milieu can also profoundly influence an implementer's willingness. This emphasis on individual motivation and internal institutional conditions implies that external policy features have limited influence on outcomes, particularly at lower level in the institution (Matland, 1995).

Moore (1995) suggests a comprehensive strategy for the implementation of public policy in order to ensure public value. This includes the equally important elements of substantive value, legitimacy and political sustainability, as well as operational and administrative feasibility. Moore (1995) refers to these linkages as the "strategic triangle" and argues that an organizational strategy is a concept that seeks to address three challenges: the mission and purpose of an organization, cast in terms of public value; the sources of support and legitimacy that will be tapped to sustain society's commitment to the organization; and the challenge of having to organize and operate the organization to achieve set objectives (Moya, 2002, p. 41). Moore (1995) asserts that policy implementation is not about operational feasibility and technical capacity, but about the substantive value of the policy. Thus, the effectiveness of implementing the TRP was 
critical in ensuring that all stakeholders had a sound buyin of government initiative in transforming the industry.

\section{Strategic implementation of the Taxi Recapitalisation Program}

Writings on the Taxi Recapitalization Program (TRP) in South Africa can be traced back to the Move South Africa (MSA) project that was designed to create a long-term (20-year) strategy to provide safe, reliable, effective, efficient and fully integrated transport operations and infrastructure. While there has been significant progress in the implementation of the program, numerous articulations argue that the program is not achieving its intended objectives.

The TRP is an intervention by the South African government to bring about safe, effective, reliable, affordable and accessible taxi operations by introducing New Taxi Vehicles (NTVs) designed to undertake public transport function in the taxi industry (www.arrivealive.co.za). It was the MSA that first suggested the government consider a recapitalisation program for the taxi industry. To give effect to the MSA, the South African Department of Transport (DoT) as the lead implementing agent of transport policy announced the TRP in 1999. The aims of the program were to:

- provide safe and affordable transport to the population already utilizing the taxi service;

- regulate the unregulated taxi industry;

- introduce cost effective fuel vehicles;

- develop downstream manufacturing and create jobs;

- introduce smart cards to the taxi industry;

- empower the taxi industry;

- and address the challenges facing people with disabilities who use minibus taxis as a means of public transport (DoT, 2003, p. 8).

After years of delays in the implementation of the TRP, the South African Cabinet announced the revised approach to the TRP in the year 2004. Smith (2005) in an article on the debriefing by Radebe (2005) on the TRP rollout strategy stated that the Department of Transport spent most of the time focusing attention on the development of a detailed TRP rollout strategy. Smith (2005) noted that the key challenges that faced the Department of Transport were the identification of potential risk factors, development of mitigating strategies and assessment of the state of readiness of the provinces. According to Smith (2005), the rollout strategy identified the need in the short-term to remove very old unroadworthy Old Taxi Vehicles (OTVs) from the South African roads. Over and above the removal of the OTVs, the revised approach entailed the:
- introduction of safety requirements for the New Taxi Vehicles (NTVs);

- scrapping of existing vehicles (OTVs);

- effective regulation of the taxi industry;

- effective law enforcement in respect of public transport; and

- empowerment of the taxi industry (www.polity.org.za).

According to Venter (2012, p. 5), the TRP has the following aim to assist and force the taxi industry to replace existing fleet with new larger and purpose built vehicles between 18 to 35 seat vehicles; scrap the OTVs and pay a scrapping incentive of R50 000; and reduce the oversupply of vehicles and improve safety of vehicles. Cambridge (2000, p. 4) in Kgamanyane (2011, p. 23) agrees with Venter on the aims of the program in that it is intended to reduce the oversupply and improve safety. However, Cambridge (2000, p. 6) further states that the TRP also aims to improve the quality of service of the taxis; ensure affordability of operations; improve the convenience to travelers; migrate from to a cashless fare payment system; ensure that operators pay their taxes and monitor route operations, usage and revenue.

Based on the above approach, Matebesi (2007, p. 7) perceives the TRP as a comprehensive activity by government to regulate the taxi industry with a view to providing safe, affordable transport to the population already utilizing taxi transport. Other than the safety aspect of the program, the program was developed jointly by the Department of Transport, Trade and Industry, Minerals and Energy and Finance, government promised to subsidise the existing taxi owners to help them to buy the new taxi vehicles. According to Baloyi (2012, p. 2), the program includes taking the taxi fleet off the road by the year 2012 and replacing them with larger, stronger, safer equipped with smart cards to ensure they stick to registered routes.

Baloyi (2012, pp. 2-3) further observes that in the TRP, operators who wish to reduce their fleet by partly existing and partly remaining were given a chance. An operator that has a fleet of taxis and wants to surrender two of his taxis can do so and still remain in the industry to continue doing business with the remaining taxis that are operating legally. According to Baloyi, the second process in the ultimate recapitalization of the taxis belonging to operators who wish to replace their vehicles with the New Taxi Vehicles and using the R50 000 per legal taxi as deposits to purchase the New Taxi Vehicle. Cambridge (2000, p. 4), in Kgamanyane (2011, p. 23), mentions that the TRP needs to be seen within the context of an integrated intermodal transport system. Cambridge (2000) argues that the inclusion of the TRP in an integrated system would enhance customer convenience and service 
credibility. While the proposal by Cambridge is excellent, the taxi industry vehemently opposed the implementation of integrated system through the Bus Rapid Transit. In her article on government's unintended consequences of the TRP, Boudreaux (2006) stresses that government's TRP is supposed to fix a set of problems that plague the South African taxi/minibus industry. Taxi violence, unsafe vehicles, and bad driving habits among taxi operators combine to make the industry unpopular and, in some cases, unsafe. For government to be able to overcome and resolve the taxi industry challenges, it would need to come up with a number of initiatives and use best practise models to ensure effectiveness and efficiency.

According to Kgamanyane (2011, p. 23), the TRP aims to improve the quality of service of the taxis; improve safety and convenience of travellers and affordable taxi operations; facilitate tax compliance by operators; monitor route operations and the revenue generated by the taxi industry. On the other hand, Fourie (2005, p. 10) argue that even though the program is extensive, the program deals mainly with the replacement of the ageing taxi fleet, but does not address issues such as the destructive competition and route rationalization. Furthermore, the recapitalisation program aims to revamp the taxi fleet through a capital injection of a maximum of R7 billion - but the plan does not deal with the consolidation and coordination of other modes of public transport. The second problem with the proposed plan is that it is safety driven. Fourie, in his view, articulated and hailed the program as the first attempt by the South African government to direct large scale financial assistance to the taxi industry.

According to Fourie (2005), even though safety is a very important aspect of improving levels of service, it is not the only one. He is convinced that anything that is not profit driven would most probably become reliant on subsidies and will, therefore, not be selfsustaining. Other than subsidized vehicles, the program does not indicate how profitability will be enhanced. While the intentions behind these changes may be good, the consequences of the TRP are likely to be less salutary. The TRP will, for example, be a boon to some taxi operators and a real burden to others. Larger, wealthier operators are much more likely to be able, vehicles will cost more than R50,000, which means the operating expenses of all taxi owners will rise. These costs will likely be passed along to taxi consumers (Boudreaux, 2006, p. 1).

Meanwhile, Matebesi (2007, p. 9) argues that the program is not appreciated by the taxi industry because of its complex nature of the TRP and significant progress made by government since the adoption of the strategy for the roll out of the program. Albeit, Matebesi (2007) states that during the launch and implementation of the program, not all the vehicles were fully compliant to the safety requirements. Most writers on the subject including taxi operators consider the TRP as not beneficial to all beneficiaries.

Bouderaux (2006) cited in Venter (2012, p. 5) criticized the program for not achieving the planned numbers for scrapping per annum, for job losses, creation of demand for illegal operations which could raise the barrier to entry and lead to the resurfacing of taxi violence. Boudreaux (2006) argues that the TRP will harm small-scale taxi entrepreneurs. The requirement that owners turn in old vehicles and replace them with big, new minibuses will simply be too onerous for many current operators. Some legitimate taxi operators will go out of business and this will have an impact on people such as drivers, mechanics, minibus washers, hawkers and others, whose livelihoods are tied to the taxi industry. On the basis that fares are likely to rise due to increased operating costs, unlicensed "pirate" taxis will troll the roads looking to carry those passengers who don't want to pay the higher fares for the newer licensed taxis.

Kgamanyane (2011, p. 34) notes that the TRP is a change program that was called upon by the change of political climate in the South Africa. With the implementation of the TRP, the taxi industry was going to be affected by the change, hence, the emotional turmoil and aggression trying to undermine that change. It is necessary that government engages meaningfully with taxi operators and makes sufficient funding available to properly formalize the taxi industry. A new process of consultation with taxi operators and their representatives is necessary to determine who represents the industry and what their needs are. In the first instance, South African National Taxi Council's dissatisfaction with the proposed 35seater vehicle should be taken seriously.

While Fourie and Pretorius (2005) agree, they, however, argue that the TRP is set out to restructure the industry by replacing the Old Taxi Vehicles with the New Taxi Vehicles. In their deliberations, Fourie and Pretorius (2005) see the TRP as the only safety driven methodology for transport regulations.

It is for this reason that Cronin (2005) argued that the delay in the implementation is a mounting evidence of the unworkability of the project in its original form, as announced in 2004. Cronin suggests that a review and scaling-down is required, but with a continued commitment to a recapitalization program. The scaling down would include a revision of the regulatory framework. Hence, Cronin (2005) suggests that government should remain committed to the program despite it having a challenging history. In his suggestions, Cronin argues that TRP is one of those 
well-intended policies that were perhaps not thoroughly thought through and were also somewhat over-ambitious. The debate by Cronin (2005) TRP in its original format exemplified the attempt and inevitable failure of the reformed national democratic project to technically modernize the sector, under the combined class hegemony of trans-national capital, did not have unreserved support from those who were intended to be the most immediate beneficiaries. Thus, Cronin (2005) also argues that the TRP has a hallmark of a developmental state driver, top-down technocratic processes in which close collaboration between a managerialism political elite, capital and emerging national capital are assumed to be the best path to development and modernization. Boudreaux (2006) supports Cronin in that the TRP will kill taxi entrepreneurs and leave many taxi problems unresolved. Boudreaux (2006) further argues that the TRP would be a benefit to some taxi operators and a real burden to others, leading to fare hikes and increased operating expenses.

\section{Program project management in government}

Public institutions today are faced with increasingly more complex situations and issues, and the environment that they operate in is a highly turbulent one. Effectiveness and efficiency may be facilitated through the introduction of best practices that are able to optimize the management of departmental resources. In a program environment, program and project management can support the achievement of departmental goals and provide a greater assurance that resources are optimally utilized (PALAMA, 2012, p. 16).

\subsection{Implementation paradigm.}

- Initiation and definition, the way policy problems are identified and assumption and values that give shape to the definition, can have a number of important consequences. The lack of political support (lack of support) generated during this stage of process can have an important effect on policy development.

- Formulation and enactment involve the formulation of a program to respond to the demand for action, getting it in the policy agenda of the governing body that is to take action, enacting legislation to authorize the implementation and appropriating sufficient funds for implementation.

- Implementation is a long, complicated procedure that includes interpreting legislation intent, balancing statutory and execution priorities, creating administrative structures and process, reviewing congressional or parliamentary debates on policy formulation, as regulations are devised. However, the line between policy making and implementation is blurred and there is much overlap.

- Impact and evaluation - policy makers assess the strengths and weaknesses of existing policies and alter them where necessary.

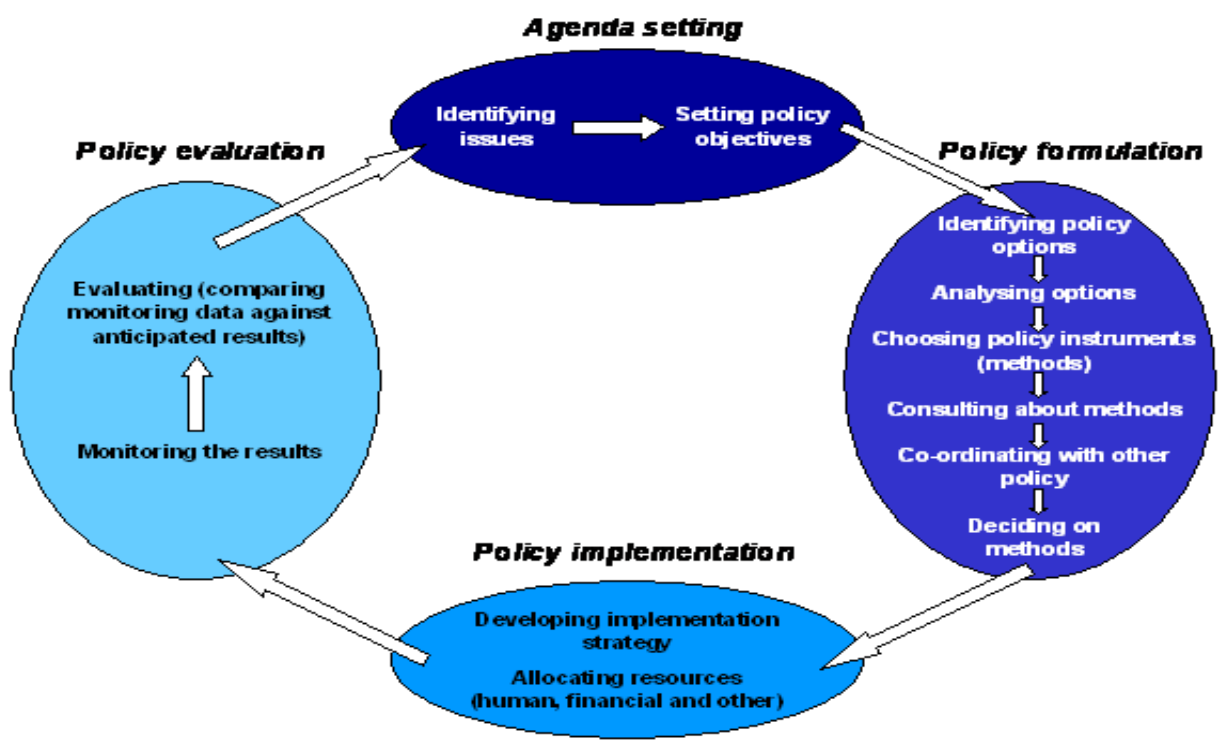

Fig. 1. The public policy cycle

Source: http://www.mfe.govt.nz/publications.

Concerning implementation, the critical difference lies in the ambitious rule-based prerogatives, which significantly augment formal pre-requisites to good public program management. The emphasis of these differences does not mean that there is a contradiction between business and public program management. It means that there are somewhat more complex demands in the pre-requisites of large-scale program management design and operations (Stemler, 2011, p. 11). 
Wideman (2004, p. 52) states that the implementing of a project management stream holds the views that program management is an extension of project management where the same principles of project management apply at every level of the hierarchy. This paper addresses the program and project interchangeably. During the literature review search, the author did not pay too much attention to the different analogy of project versus program, as the paper was emphasizing more of the need to recapitalize rather than the different notions of school of thoughts. Thus, the sections below deal with the challenges faced by SANTACO as one big stakeholder in the implementation process.

\section{Challenges facing Taxi Recapitalisation Program in SA (the SANTACO case)}

One of the major challenges facing the TRP in South Africa is based on the following:

- Maintaining the unity of the industry and, as a consequence, the peace that currently prevails.

- Implementation of the Taxi Recapitalization Program and the resolution of the EMS, regulatory framework, the scrap allowance and the subsidies.

- Rationalization of the transport agencies at provincial and national government levels (the permit boards, registrar's offices, Cross Border Road Agency).

- Dealing with corruption in the issuing of licences and permits. It is Santaco's view that this has resulted in too many licences and permits being issued. SANTACO would like to call on government to establish a commission to investigate this matter, to establish how many licences and permits have been issued to date and to recommend a more appropriate system of issuing permits and licences in the future. As SANTACO, we strongly recommend that there should be a moratorium placed on the issuing of mini-bus taxi licences and permits until this matter has been properly investigated.

- Stopping the implementation of the cooperatives concept, as this has failed to deliver benefits to the taxi industry. The only beneficiaries have been the consultants that charge exorbitant fees. The taxi industry has had the unfortunate experience of dealing with consultants who have treated the industry with a condescending knowit-all attitude to the total disregard of the inputs of the industry. This is an issue SANTACO want to bring out into the open.

- Government's commitment to SANTACO and a unified Taxi Industry. Currently the message coming from government with regard to this industry is confusing. This industry carries between $60 \%$ and $70 \%$ of black commuters in the country and yet government's response in a number of instances is at best lukewarm. A clearer position from government in this regard is needed.

- Improving Santaco's resources and revenue generating capacity and maintaining a strong and credible leadership of Santaco particularly at this early stage of Santaco's development.

- Transforming the image of the industry into one that is seen by the public and commuters as one that provides safe, secure, accessible and affordable transport services and developing an efficient and professional secretariat.

\section{Research methodology}

The objective of the article was an exploration investigating factors affecting the implementation of government's Taxi Recapitalization Program by the Department of Transport: (i) to investigate the pillars informing the implementation of the TRP, (ii) establish the role of the South African National Taxi Council (SANTACO) in the implementation of the Taxi Recapitalisation Project. The method used for this article was classified as content analysis and involved obtaining information from the literature. The literature gave an overview from both an international and national perspective, with academic books, journal articles, reports and electronic media being used for this purpose. However, the author attempted to consult the relevant available literature from researchers in the Department of Transport internationally and nationally. This article seeks to contribute to the existing literature on taxi recapitalization and provide a significant challenges facing SANTACO, as well as government and relevant stakeholders who depend on public transport in Southern Africa and to present future study and research areas.

\section{Limitations of Taxi Recapitalization Program in South Africa}

- Lack of effective working relations typically resulting from bargaining, cajoling, accommodation, threats, gestures of respect, and related transactions pose limitations in policy implementations. In short, bureaucratic contexts favorable to implementation more often grow out of human interactions than hierarchical regulation.

- Stakeholder commitment is important not only at the 'street-level', but also at all levels through which policy passes - in cases of international commitments, this would include the regimelevel, the state-level, the street-level, and all levels in between. 
- The capacity of the public sector is conceptualized in general systems thinking terms as the structural, functional and cultural ability to implement the policy objectives of the government, capacity also includes the intangible requirements of leadership, motivation, commitment, willingness, guts, endurance, and other intangible attributes needed to transform rhetoric into action. The political, administrative, economic, technological, cultural and social environments within which action is taken must also be sympathetic or conducive to successful implementation.

- Network approach to service delivery and transformation of government in order to mobilize all available resources to achieve policy objectives threatens speedy implementation and amounts to a paradigm shift regarding the nature of government.

\section{Conclusion}

This article presented the literature review on policy implementation, strategic implementation of TRP, and program management and project management in government. Secondly, the theoretical literature of the taxi industry as a key player in South Africa's society was provided. Government should acknowledge its vital role through adequate investment and by realizing a comprehensive and participatory recapitalization program. Road safety requires the active involvement and commitment from this important transport sector and that the use of every mechanism available to improve the roadworthiness of the vehicles, as well as the driving behavior be harnessed.
Implementation literature does not have sufficient theoretical structure. As a result, implementation takes different shapes and forms in different institutional settings. From various discussions, implementation can be conceptualized as process, output and outcome. A series of decisions and actions that are directed to words putting that are translated into a prior authoritative decision effect should be carefully looked to.

The literature has further shown that TRP is a comprehensive intervention by the South African democratic government to regulate the taxi industry with a view of providing a safe, affordable transport to the population already utilizing taxis. The fundamental issue surrounding the TRP should be geared towards the effectiveness and efficiency of the program.

Program management is viewed as an important ingredient for policy implementation. If coupled with other instruments for policy implementation such as strategy formation, project management has a potential to improve service delivery.

Although South Africa is a giant economy and in a class of its own in Africa, unemployment remains a thorny issue and most of the taxi industry is infiltrated by illegal irregularities and violence. Therefore, complaisance by taxi owners towards TRP is a necessity in order to achieve the desired objective of the Department of Transport in providing safe, reliable and affordable transport to the majority of public transport users in South Africa.

Policy makers are still struggling to regularize the industry that leaves many of the road stranded almost on daily basis. The Bus Rapid Transit has not meaningfully alleviated the problems faced by Department of Transport in SA.

\section{References}

1. Allopi, D. (2006): Towards a Safer Minibus Taxi Industry in South Africa. Available at: http://repository.up.ac.za/upspace/bitstream/2263/6052/1/022.pdf. Accessed on 30 June 2010.

2. Baloyi, D. (2012). The Taxi Recapitalisation Summit. South Africa: DoT.

3. Boudreaux, K. (2006). The Unintended Consequences of Taxi Recapitalisation Project. Free Market FoundationNews Article. Available at: http://www.marketfoundation.com. Accessed on the 29 August 2011

4. Cronin, J. (2005). The People shall Govern - Class Struggle and Post-1994 State in South Africa. Available at: http://www.amandlawonke.wikispaces.com/2005. Accessed on the $27^{\text {th }}$ August 2011.

5. Department of Transport (DoT). (2009). Taxi Recapitalization Policy Document. Approved by Cabinet of South Africa.

6. Department of Transport (DoT). (2003). National Household Travel Survey report. South Africa: DoT Publications.

7. Dlamini-Mokhele, N. (2008). Impact of Taxi Recapitalisation Strategy on Expenditure Patterns and Poverty levels of Taxi-mode Commuters in the Vaal. Philosophaie Doctor: North-West university, South Africa.

8. Fourie, L.J. and Pretorius, P.J. (2005). A Call for the Radical Restructuring of the Mini-bus Taxi Industry in South Africa, South African Journal of Industrial Engineering, 16 (1), pp. 1-11.

9. Fourie, L.J. (2004) Challenges facing implementation of TRC. South African Transport.

10. Kgamanyane. (2011). Taxi recapitalisation industry, Trends and Analysis Stats Review, p. 23.

11. Giacchino, S., Kakabadse, A. (2003). Successful policy implementation: the route to building self-confident government, International Review of Administrative Sciences, 69 (2), pp. 139-160.

12. Govender, R. and Allopi, D. (2006). Towards a Safer Minibus Taxi Industry in South Africa. Pretoria: Unpublished Dissertation, University of Pretoria. 
13. Mabitsela, L. (2003). Exploratory Study of Psychological Distress As Understood by Pentecostal Pastors. Pretoria: University of Pretoria.

14. Magubane, N. \& Manicom, D. (2003). Taxi-Owners Perceptions of the Government Taxi Recapitalization Scheme: A case sturdy of taxi owners in Pietermaritzburg. Proceedings of the 22nd Southern African Transport Conference (SATC2003) $14^{\text {th }}-16^{\text {th }}$ July 2003, Pretoria, South Africa.

15. Makae, I. (2009) The impact of Public Policy on competing interests. A Case Study of the Taxi Recapitalization Project. Unpublished thesis. Durban: University of KwaZulu-Natal.

16. Mashiloane, P. (1998) An investigation Into Conflict and Violence in the Mini-bus Taxi Business in Soshanguve Area. MA Dissertation. Pretoria: University of Pretoria.

17. Matland, E.R. (1995). Synthesizing the implementation literature: The ambiguity-conflict model of policy implementation, Journal of Public administration Research and Theory, 5 (2), pp. 145-174.

18. Mazmanian, D.A. \& Sabatier, P.A. (1983). Implementation and Public Policy. USA: University Press of America.

19. Moleketi, G. (2003) Project Management in the Public Sector. Proceedings of IQPC Project Management held in Sandton, South Africa.

20. Moyake, M.S. (2006). A Critical Analysis of the Taxi Recapitalisation Policy. BA Dissertation. Vaal Triangle: North-West University.

21. Mpofu, M. (2012). The Taxi Recapitalisation Summit. SA

22. Newman, W.H. (1987). Project Management: Strategic Design and Implementation. $2^{\text {nd }}$ edition. USA: Mc-Graw Hill, Inc.

23. PALAMA. (2012). Africa, Blog, Johannesburg, South Africa.

24. Presidency of South Africa. (2003). Towards a Ten Year Review: Discussion Document. Published by GCIS

25. Ramchander, P. (2004). Towards the Responsible Management of the Socio-Cultural Impact of Township Tourism. Unpublished dissertation. Faculty of Economic and Management Sciences. University of Pretoria

26. Radebe, J. (2004): Government Statement on the Taxi Recapitalization Project (TRP). Available at: http://www.archive.pmg.org.za/briefings/briefings.

27. Radebe, J. (2012). Debriefing of TRP summit in Gauteng. South Africa.

28. Stemler, E. (2011). Program Management Design. South Africa.

29. Van Meter, D.S. \& Van Horn, C.E. (1974). Administration and the 1974 Annual Meeting of the American Political Science Association. Available at: http://www.sagepub.com/journalsPermissions.

30. Venter, I. (2009). Engineering News. Creamer Media. Available at: http://www.engineeringnews.co.za. Accessed on 24 February 2010

31. Wideman, M. (2002). Wideman Corporate Glossary of Project Management Terms version 3. Available at: www.maxiwideman.com/pmg/PMG p12.htm. Accessed on 24th August 2011.

32. Wirik, D. (2009). Public-Sector Project Management: Meeting the Challenges and Achieving Results. Hoboken, New Jersey and Canada: John Wiley \& Sons Inc. 